\title{
Outcome after severe multiple trauma: a retrospective analysis
}

\author{
Christian von Rüden ${ }^{1 *}$, Alexander Woltmann ${ }^{1}$, Marc Röse ${ }^{1,2}$, Simone Wurm¹, Matthias Rüger ${ }^{1}$, \\ Christian Hierholzer ${ }^{1}$ and Volker Bühren ${ }^{1}$
}

\begin{abstract}
Background: Aim of this study was to evaluate prognosis of severely injured patients.

Methods: All severely injured patients with an Injury Severity Score (ISS) $\geq 50$ were identified in a 6-year-period between 2000 and 2005 in German Level 1 Trauma Center Murnau. Data was evaluated from German Trauma Registry and Polytrauma Outcome Chart of the German Society for Trauma Surgery and a personal interview to assess working ability and disability and are presented as average.
\end{abstract}

Results: 88 out of 1435 evaluated patients after severe polytrauma demonstrated an ISS $\geq 50$ (6.5\%), among them $23 \%$ women and $77 \%$ men. 66 patients (75\%) had an ISS of 50-60, 14 (16\%) 61-70, and 8 (9\%) $\geq 70$. In 27\% of patients trauma was caused by motor bike accidents. 3.6 body regions were involved. Patients had to be operated 5.3 times and were treated 23 days in the ICU and stayed 73 days in hospital. Mortality rate was 36\% and rate of multi-organ failure $28 \% .15 \%$ of patients demonstrated severe senso-motoric dysfunction as well as residues of severe head injury. 25\% recovered well or at least moderately. 29 out of 56 survivors answered the POLO-chart. A personal interview was performed with 13 patients. The state of health was at least moderate in $72 \%$ of patients. In $48 \%$ interpersonal problems and in $41 \%$ severe pain was observed. In $57 \%$ of patients problems with working ability regarding duration, as well as quantitative and qualitative performance were observed. Symptoms of posttraumatic stress disorder were found in $41 \%$. The more distal the lesions were located (foot/ankle) the more functional disability affected daily life. In only 15\%, working ability was not impaired. 8 out of 13 interviewed patients demonstrated complete work disability.

Conclusions: Even severely injured patients after multiple trauma have a good prognosis. The ISS is an established tool to assess severity and prognosis of trauma, whereas prediction of clinical outcome cannot be deducted from this score.

Keywords: Severe multiple trauma, ISS, POLO-chart, Post-traumatic stress disorder

\section{Background}

According to recent WHO calculations approximately 5.800.000 people die per year as a consequence of trauma [1]. In Germany approximately $80 \%$ of traumatic injuries are caused following motor vehicle accidents [2]. In last three decades mortality following multiple trauma decreased from over $40 \%$ to $15 \%$ as a consequence of improved structural and personal manage and treatment conditions $[3,4]$. Survival after major trauma may result

\footnotetext{
* Correspondence: christian.vonrueden@bgu-murnau.de

'Department of Trauma Surgery, Murnau Trauma Center, Murnau 82418, Germany

Full list of author information is available at the end of the article
}

in life-time psychological distress and/or physical impairment often associated with working disability [5]. Therefore, treatment of severely injured patients with an Injury Severity Score (ISS) $\geq 16$ is very challenging both from a medical and also economic point of view [6,7]. The ISS system allocates the Abbreviated Injury Scale (AIS) scores into six body regions and calculates the highest AIS score from the three most severely injured ISS body regions to assign the ISS score in an ordinal scale from $1=$ minor to $75=$ lethal [8].

Aim of this study was to evaluate prognosis of severely injured patients with an ISS $\geq 50$, incidence of severe multiple trauma, trauma mechanisms as well as mortality,

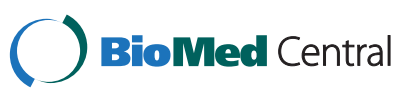


invalidity, working ability/disability and quality of life after survival and reconvalescence of major trauma.

\section{Methods}

\section{Study population}

In a retrospective 6-year-cohort-study following the STROBE/EQUATOR checklist patients with severe multiple trauma and ISS $\geq 16$ were evaluated in Level 1 Trauma Center Murnau, Germany, between 01/2000 and $12 / 2005$. Due to an internal consensus that usually the cut-off for deadly severe multiple trauma is an ISS of about 40, all Patients with an ISS $\geq 50$ (and therefore much higher than the common cut-off) were included in the study. Data analysis focused on pattern of injury, involved body regions, days in intermediate care unit (ICU), clinical outcome, and final outcome of mental condition. Average time of prospective follow up was 3.6 years after trauma (range 18-78 months).

\section{Data source}

Patients' data was evaluated from data collected by Murnau Trauma Center and transferred to the German Trauma Registry as well as the "Polytrauma Outcome (POLO) Chart" of the German Society for Trauma Surgery, and a personal interview [9]. Written informed consent was obtained from the patients for publication of this report and any accompanying images. Ethical clearance was obtained from Institutional Ethical Committee, and the study adhered to the tenets of the Declaration of Helsinki.

\section{Abbreviated Injury Scale (AIS)}

The AIS classifies injuries in type of anatomic structure, specific structure, body regions, and level and assigns severity in an ordinal scale from $1=$ minor to $6=$ lethal [8].

\section{POLO chart}

POLO chart includes the Glasgow Outcome Scale (1 item), the Quality of life index (5 items), the SF-36 (36 items), and the Trauma Outcome Profile (57 items, including the dimensions depression, anxiousness, posttraumatic stress disorder (PTSD), social aspects, pain, body function, activities, and mental function. A multidimensional evaluation using the POLO Chart questionnaire was performed in 29 out of 56 survivors with an ISS $\geq 50$ to assess health-based quality of life state. All patients who filled out the POLO Chart questionnaire were asked to take part in a personal interview. 13 out of these 29 patients were available by phone and gave their permission.

\section{Glasgow Outcome Scale (GOS)}

The Glasgow Outcome Scale designed in 1975 by Jennett and Bond [10], is an important outcome parameter for further evaluation (including the parameters death, unconsciousness, strong handicap, fair handicap, well recovery), and is evaluated since 2002 as part of the POLO chart. This comparatively simple score became accepted in recent years although criticized due to its numerous subjective variables. 13 out of these 29 survivors with an ISS $\geq 50$ additionally underwent a personal interview including four questions about working ability:

1. Are you back in your job again?

2. If yes, do you perform the same job or did you have to change into another job?

3. How long did it take to re-entry into your job?

4. If no, how was level of invalidity (i.e. level of disability of work due to the accident)?

\section{Statistical analysis}

Statistical analysis was performed using SPSS $^{\circ}$ (SPSS, Chicago, Illinois, U.S.A.), and graphs using Excel 2010 for Windows XP (Microsoft, Redmond, Washington, U. S.A.). Results in this study were mentioned as mean values. Significance was statistically calculated based on Pearson's chi-squared test and t-test. A result was considered to be statistically significant with $\mathrm{p}$-value $<0.05$. Incidence rates and categorical variables were compared using the Mann-Whitney-test. Reference group included all treated polytraumatized patients with ISS $\geq 16<50$ in Murnau Trauma Center in the same time period $(1435-88=1347$ patients $)$.

\section{Results}

Patients and demographic characteristics

In Germany 50.000 people per year suffer a major trauma [11]. Based on this calculation, incidence of severe multiple trauma with an ISS $\geq 50$ is about 3.265 patients per year. In our institution 88 out of 1435 evaluated patients after severe multiple trauma (6.5\%) demonstrated an ISS $\geq$ 50. 66 patients (75\%) had an ISS of 50-60, $14(16 \%)$ $61-70$, and $8(9 \%) \geq 70.20$ patients $(23 \%)$ were women and $68(77 \%)$ were men with a age of 40 years ( \pm 17 years, range 18-63) on average. In the group of patients with an ISS $\geq 50$, ISS was 56.8 on average, whereas in patients with an ISS < 50, ISS was 24.3 on average. Parameters of all included individuals of both groups (ISS $\geq 50$ and ISS $<50$ ) are listed in Table 1.

\section{Mechanism of injury}

55 out of 88 patients were involved in an accident. In 9 patients suicide was causative and in 24 patients other causes. In 15 patients (27\%) major trauma was caused by motor bike accidents, in 19 patients (35\%) by car accidents, in 3 patients $(5 \%)$ by bicycle accidents and in 9 patients (16\%) by fall from a height (in 18\% of patients no conclusive data were found; Figure 1). Motor cycle 
Table 1 Overview of all included parameters of patients after major trauma 2000-2005 comparing both groups, ISS $\geq \mathbf{5 0}$ and ISS $<\mathbf{5 0}$

\begin{tabular}{|c|c|c|c|c|c|c|c|}
\hline ISS $\geq 50$ vs. ISS $<50$ & ISS $<50$ & & & ISS $\geq \mathbf{5 0}$ & & & Chi-squared test or $t$-test \\
\hline 1435 patients & number & mean & $\%$ & number & mean & $\%$ & significance (p) \\
\hline Total & 1347 & & $93.9 \%$ & 88 & & $6.1 \%$ & \\
\hline Male & 1004 & & $74.5 \%$ & 68 & & $77.3 \%$ & 0.83 \\
\hline Female & 343 & & $25.5 \%$ & 20 & & $22.7 \%$ & 0.66 \\
\hline \multicolumn{8}{|l|}{ ISS } \\
\hline$<20$ & 556 & & $41.3 \%$ & & & & \\
\hline $21-40$ & 688 & & $51.1 \%$ & & & & \\
\hline $41-49$ & 103 & & $7.6 \%$ & & & & \\
\hline \multicolumn{8}{|l|}{ Mechanism of trauma } \\
\hline Car/truck & 365 & & $27.1 \%$ & 31 & & $35.2 \%$ & 0.23 \\
\hline Motor cycle & 212 & & $15.7 \%$ & 24 & & $27.3 \%$ & 0.023 \\
\hline Bicycle & 96 & & $7.1 \%$ & 4 & & $4.5 \%$ & 0.39 \\
\hline Pedestrian & 44 & & $3.3 \%$ & 7 & & $8.0 \%$ & 0.029 \\
\hline Fall $>3 \mathrm{~m}$ & 198 & & $14.7 \%$ & 14 & & $15.9 \%$ & 0.79 \\
\hline Fall $<3 \mathrm{~m}$ & 195 & & $14.5 \%$ & 1 & & $1.1 \%$ & 0.0012 \\
\hline Other & 237 & & $17.6 \%$ & 7 & & $8.0 \%$ & \\
\hline \multicolumn{8}{|l|}{ Pattern of injury } \\
\hline Head/brain & 689 & & $51.2 \%$ & 48 & & $54.5 \%$ & 0.73 \\
\hline Face & 252 & & $18.7 \%$ & 19 & & $21.6 \%$ & 0.58 \\
\hline Chest & 450 & & $33.4 \%$ & 49 & & $55.7 \%$ & 0.0057 \\
\hline Abdomen & 211 & & $15.7 \%$ & 30 & & $34.1 \%$ & 0.00039 \\
\hline Spinal cord & 360 & & $26.7 \%$ & 30 & & $34.1 \%$ & 0.27 \\
\hline Pelvis & 179 & & $13.3 \%$ & 27 & & $30.7 \%$ & 0.00025 \\
\hline Upper limb & 311 & & $23.1 \%$ & 25 & & $28.4 \%$ & 0.38 \\
\hline Lower limb & 315 & & $23.4 \%$ & 27 & & $30.7 \%$ & 0.23 \\
\hline Soft tissues & 266 & & $19.7 \%$ & 25 & & $28.4 \%$ & 0.12 \\
\hline Primarily unconscious patients (GCS $<=8$ ) & 245 & & $18.2 \%$ & 41 & & $46.6 \%$ & 0.0000015 \\
\hline Intubation rate & 648 & & $48.1 \%$ & 66 & & $75.0 \%$ & 0.0084 \\
\hline Reanimation rate & 18 & & $1.3 \%$ & 8 & & $9.1 \%$ & 0.0000005 \\
\hline Secondarily transferred patients & 548 & & $40.7 \%$ & 36 & & $40.9 \%$ & 0.98 \\
\hline Preclinical shock (BP systolic $<90 \mathrm{mmHg}$ ) & 73 & & $5.4 \%$ & 16 & & $18.2 \%$ & 0,000017 \\
\hline Duration until organ failure & & days & & & days & & \\
\hline Lung & 209 & 9.5 & $15.5 \%$ & 27 & 9.1 & $30.7 \%$ & 0.0028 \\
\hline Coagulation/Blood & 44 & 3.5 & $3.3 \%$ & 11 & 1.7 & $12.5 \%$ & 0.000051 \\
\hline Liver & 30 & 11.6 & $2.2 \%$ & 2 & 2 & $2.3 \%$ & 0.98 \\
\hline Circulation & 178 & 8.1 & $13.2 \%$ & 31 & 8.1 & $35.2 \%$ & 0.0000058 \\
\hline Central nervous system & 156 & 14.9 & $11.6 \%$ & 27 & 20 & $30.7 \%$ & 0.000019 \\
\hline Kidney & 66 & 8.9 & $4.9 \%$ & 4 & 5 & $4.5 \%$ & 0.89 \\
\hline SIRS & 51 & 8.7 & $3.8 \%$ & 11 & 11.5 & $12.5 \%$ & 0.00032 \\
\hline Duration of intubation & 944 & 13.4 & & 77 & 20.3 & & 0.0000094 \\
\hline Lethality/Dead & 179 & & $13.3 \%$ & 32 & & $36.4 \%$ & 0.0000024 \\
\hline Early lethality ( $<24 \mathrm{~h}$ after hospital admission) & 46 & & $3.4 \%$ & 12 & & $13.6 \%$ & 0.000014 \\
\hline Time in hospital & & 49.1 & & & 73.4 & & 0.0002158 \\
\hline Time on intensive care unit & & 14.4 & & & 25.9 & & 0.0000057 \\
\hline Involved body regions & & 2.3 & & & 3.8 & & 3.09444E-29 \\
\hline
\end{tabular}


Table 1 Overview of all included parameters of patients after major trauma 2000-2005 comparing both groups, ISS $\geq \mathbf{5 0}$ and ISS $<\mathbf{5 0}$ (Continued)

\begin{tabular}{|c|c|c|c|c|c|c|}
\hline Operations per patient & & & & 5.7 & & $6.25 \mathrm{E}-08$ \\
\hline \multicolumn{7}{|l|}{ Aim of discharge } \\
\hline Home & 512 & $38.0 \%$ & 23 & & $26.1 \%$ & 0.12 \\
\hline Rehabilitation hospital & 449 & $33.3 \%$ & 20 & & $22.7 \%$ & 0.13 \\
\hline Other hospital & 184 & $13.7 \%$ & 11 & & $12.5 \%$ & 0.79 \\
\hline Other & 7 & $0.5 \%$ & 0 & & $0 \%$ & \\
\hline Dead & 179 & $13.3 \%$ & 32 & & $36.4 \%$ & \\
\hline Unknown & 16 & $1.2 \%$ & 2 & & $2.3 \%$ & \\
\hline \multicolumn{7}{|c|}{ Status after discharge due to GOS } \\
\hline Well recovered & 509 & $37.8 \%$ & 20 & & $22.7 \%$ & 0.036 \\
\hline Moderately affected & 92 & $6.8 \%$ & 3 & & $3.4 \%$ & 0.21 \\
\hline Heavily affected & 125 & $9.3 \%$ & 13 & & $14.8 \%$ & 0.07 \\
\hline Unconscious & 29 & $2.2 \%$ & 2 & & $2.3 \%$ & 0.98 \\
\hline Dead & 106 & $7.9 \%$ & 20 & & $22.7 \%$ & 0.00013 \\
\hline Unknown & 53 & $3.9 \%$ & 4 & & $4.5 \%$ & \\
\hline
\end{tabular}

accidents were significantly more often causative for multiple trauma with ISS $\geq 50$ than ISS $<50$ (p-value $<0.05$ ). In all patients trauma was blunt. No penetrating trauma was observed.

\section{Pre-hospital}

$18 \%$ of patients with ISS $\geq 50$ demonstrated pre-hospital shock symptoms, defined as systolic blood pressure $<90$ mmHg according to German Trauma Registry, compared with $5 \%$ in patients with ISS $<50$ (p-value $<0.05$ ).

Primary loss of consciousness at the sight of trauma was observed in $50 \%$ of patients with ISS $\geq 50$ (Glasgow Coma Scale $\leq 8$ ) compared with $30 \%$ in patients with ISS $\leq 50$.

Pre-hospital intubation rate was significantly higher in patients with ISS $\geq 50$ (75\%) compared with patients with ISS $<50$ (48\%; p-value $<0.05)$. Cardio- pulmonary resuscitation was required in $9 \%$ of all patients with ISS $\geq 50$, but only in $1 \%$ of patients with ISS $<50$ (p-value $<0.05$ ).

Rate of secondary transfer of patients to our national Level 1 Trauma Center was $41 \%$ in the group of patients with ISS $\geq 50$ compared with $40 \%$ in the group of patients with ISS $<50$.

\section{Intensive Care Unit (ICU)}

Type of organ failure is a pivotal parameter for prognosis and outcome in severely injured patients. Lesions of circulation, airway, coagulation and central nerve system (CNS) play a decisive role in severely injured patients with ISS $\geq 50$ ( $\mathrm{p}$-value $<0.05$; Figure 2 ). Rate of organ failure in all patients with ISS $\geq 50$ was $54 \%$. In all patients who died following multiple trauma, rate was $78 \%$. Rate of multi-organ failure was $31 \%$ in patients with ISS

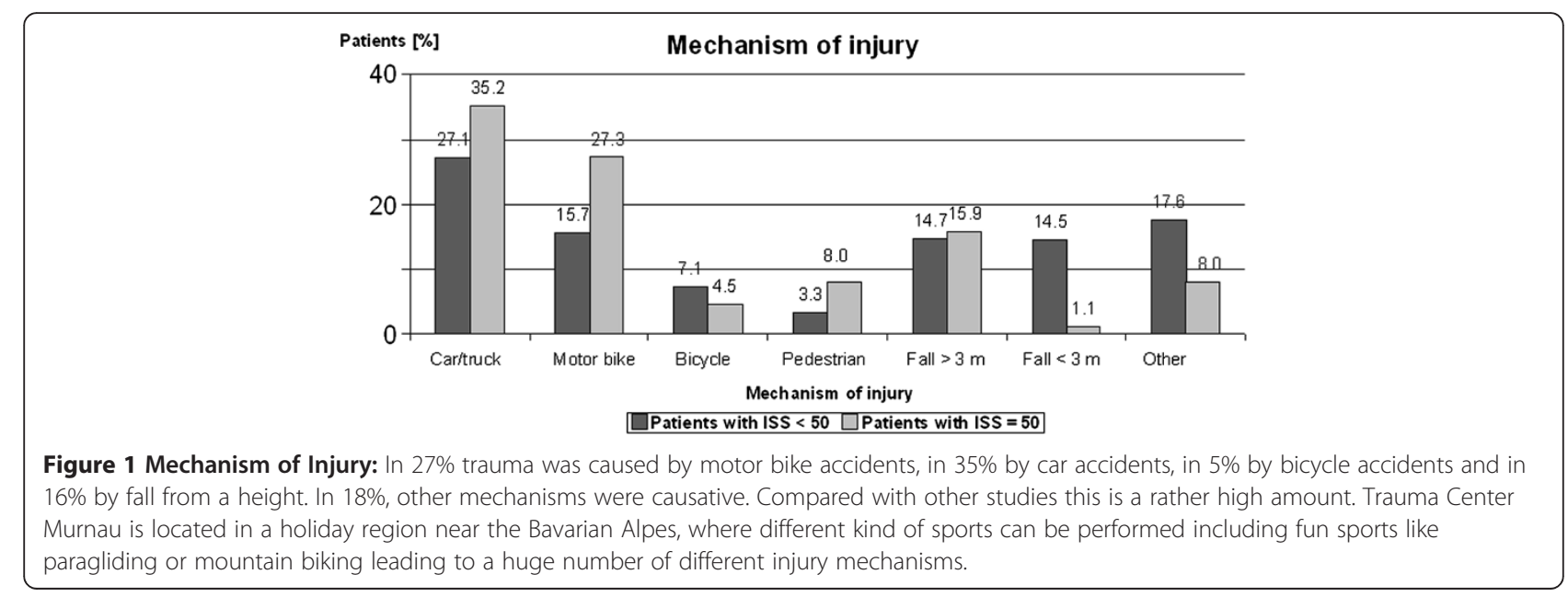


$\geq 50$ compared with $10 \%$ in patients with ISS $<50$ (p-value $<0.05$ ). Sepsis was found in $13 \%$ of cases with ISS $\geq 50$ compared with $4 \%$ in case of ISS $<50$ (p-value $<$ $0.05)$. Duration of intubation/ventilation in ICU was significantly longer in patients with ISS $\geq 50$ (20 days on average) compared with patients with ISS $<50$ (13 days on average; p-value $<0.05)$. Mortality of patients with ISS $\geq 50$ was significantly higher (36\%) than in patients with ISS < 50 (13\%; p-value < 0.05). Early mortality in primary cases within the first 24 hours after hospitalization was dependent on ISS. Early mortality in patients with ISS $\geq$ 50 was significantly higher (13\%) than in patients with ISS $<50$ (3\%; p-value < 0.05).

\section{Hospital}

Between 2000 and 2005 duration of hospital treatment of severely injured patients' time in hospital was 51 days on average including treatment of 15 days in ICU. In patients with ISS $\geq 50$ the hospital course was 73 days. These patients were treated 23 days in the ICU and therefore 10 days longer in the ICU compared with patients with ISS $<50$ who were treated 49 days in hospital and 13 days in the ICU (p-value $<0.05$ ). Most patients with ISS $\geq 50$ were discharged into ambulatory care, $23 \%$ to a rehabilitation clinic, $13 \%$ were transferred to another hospital and 36\% died in hospital. According to ISS regions, in patients with ISS $\geq 503.8$ body regions were involved compared to 2.3 body regions in patients with ISS $<50$ (p-value $<0.05$ ). In $82 \%$ of all severely injured patients primary operative intervention was performed in Murnau Trauma Center. On average, 3.6 operations were performed per patient. In all patients with ISS $\geq 50$ the severity of injury required primary operative therapy followed by 5.7 consecutive operations (p-value $<0.05$ ). Analysis of the multiple trauma injuries revealed a distinct pattern was very special in patients with ISS $\geq 50$ : Thoracal lesions were found significantly more often than in patients with ISS < 50 (94\% vs. $44 \%$ ), the same phenomenon was seen in lesions of the lower extremities (64\% vs. $32 \%)$, the spinal cord (69\% vs. $37 \%)$, the abdomen ( $50 \%$ vs. $13 \%)$, the upper extremities ( $44 \%$ vs. $29 \%)$, and the soft tissues ( $10.5 \%$ vs. $4.5 \%$; p-value < 0.05 ; Figure 3 ). The most frequent injury patterns in patients with ISS $\geq 50$ were combined lesions of chest/ lower extremities (60\%) and chest/spinal cord (56\%). These combinations of injury occurred more frequently than in patients with ISS $<50$ (p-value $<0.05$; Figure 4 ).

\section{Abbreviated Injury Scale (AIS)}

Assessment of severity of organ injury demonstrated an AIS score [12] of 4.2 for lesions of the head, 1.7 for face/ neck, 4.1 for thorax, 4.0 for abdomen, 4.4 for spinal cord, 2.1 for upper extremities, 3.9 for lower extremities and 2.0 for soft tissues/other in patients with ISS $\geq 50$ compared to an AIS score of 3.8 for lesions of the head, 1.7 for face/neck, 3.3 for thorax, 3.3 for abdomen, 3.4 for spinal cord, 2.1 for upper extremities, 3.0 for lower extremities and 1.6 for soft tissues/other in patients with ISS $<50$ (p-value $<0.05)$.

\section{Glasgow Outcome Scale (GOS)}

$38 \%$ of patients with ISS $<50$ discharged from hospital well recovered, but just $23 \%$ patients with ISS $\geq 50$ (p-value $<0.05$ ).

\section{POLO chart, trauma outcome profile, SF-36}

$28 \%$ of patients reported memory of the sequence of events of the accident. On average 3.6 years after trauma, in 8 out of 29 patients (28\%) subjective assessment was bad, and at least moderate in $72 \%$. In $48 \%$ impairment of interpersonal contacts following physical and/ or psychological problems and in $62 \%$ pain (41\% severe pain) was observed (Figure 5). Clinical symptoms of depression (48\%), increased anxiousness (45\%), posttraumatic stress disorder $(41 \%)$ and social problems (28\%) were observed [13]. In 57\% problems in working ability concerning duration, as well as quantitative and qualitative performance were assessed. The more distal the lesions were located (foot/ankle) the more functional disability affected daily life.

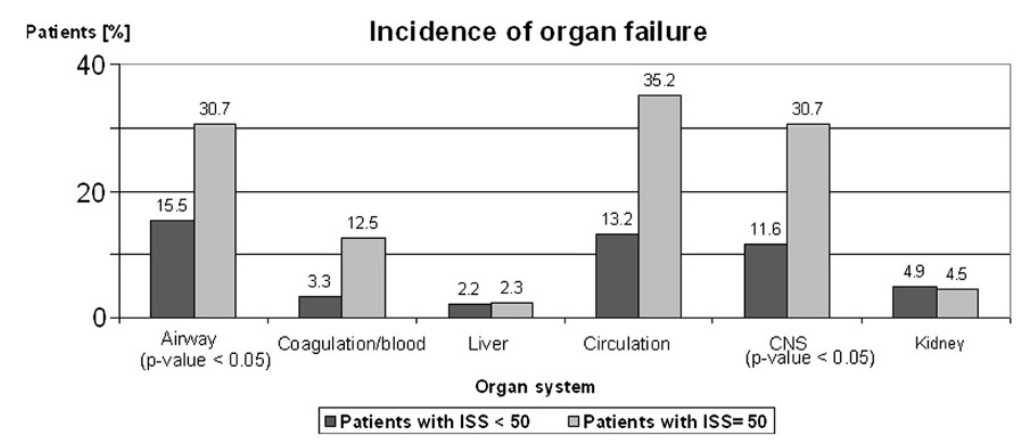

Figure 2 Incidence of organ failure: Kind of organ failure is a pivotal parameter for prognosis and outcome in severely multiple-injured patients. Lesions of circulation, airway, coagulation and central nerve system (CNS) play a decisive role in severely multiple-injured patients. 


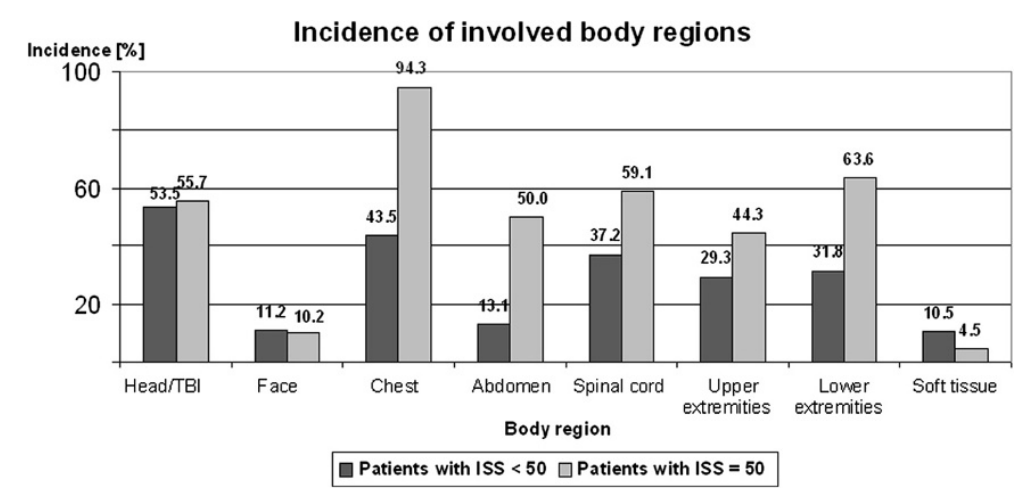

Figure 3 Incidence of involved body regions: Injury pattern was very specific in patients with ISS $\geq 50$. Mean incidence of involved body regions was significantly higher in patients with ISS $\geq 50$ compared with patients with ISS $<50$.

\section{Personal interview}

A personal interview was performed with 13 out of 29 patients who had answered the POLO Chart questionnaire. In only $15 \%$, working ability was not impaired. Time to re-entry into work was 24 months on average. 8 out of 13 interviewed patients demonstrated complete work disability.

\section{Discussion}

Outcome after severe multiple trauma is the result of many diagnostic and therapeutic steps over a long time period beginning with the emergency treatment at place of accident until end of rehabilitation. Little is known about final functional outcome of patients after severe multiple trauma. Such information is very important, because severely injured patients often are young, and the majority belongs to the working population [14]. The severity of an injury is one of the parameters determining the outcome of injury. To what extent the severity of an injury affects the outcome is rather unclear yet. It is well known that survival chances of severely injured patients have improved continuously during recent years.
Therefore, not only the question of whether, but also how a severely multiple-injured patient survives is of specific interest nowadays ongoing with increasing survival rates. The outcome includes not only physical, but also psychological and social aspects and chronic pain. Studies in the past focused on the influence of psychological or social factors for clinical outcome. Also the pre-traumatic clinical status and accompanying diseases are established factors for prediction of functional outcome in severely injured patients [15]. Our results concerning trauma mechanism showed that an extraordinary amount of severe multiple traumas were caused by motor cycle accidents. Besides, motor cycle accidents were significantly more often causative for major trauma in patients with ISS $\geq 50$ than ISS $<50$. Our results also showed that in patients with ISS $\geq 50$ lesions of the extremities more often were caused by motor bike than by car accidents, which probably is related to a loss of effective protection for these regions of the body. In general, changing of injury patterns during last decades is based on multiple factors: Progress in vehicle and road construction continuously influenced injury

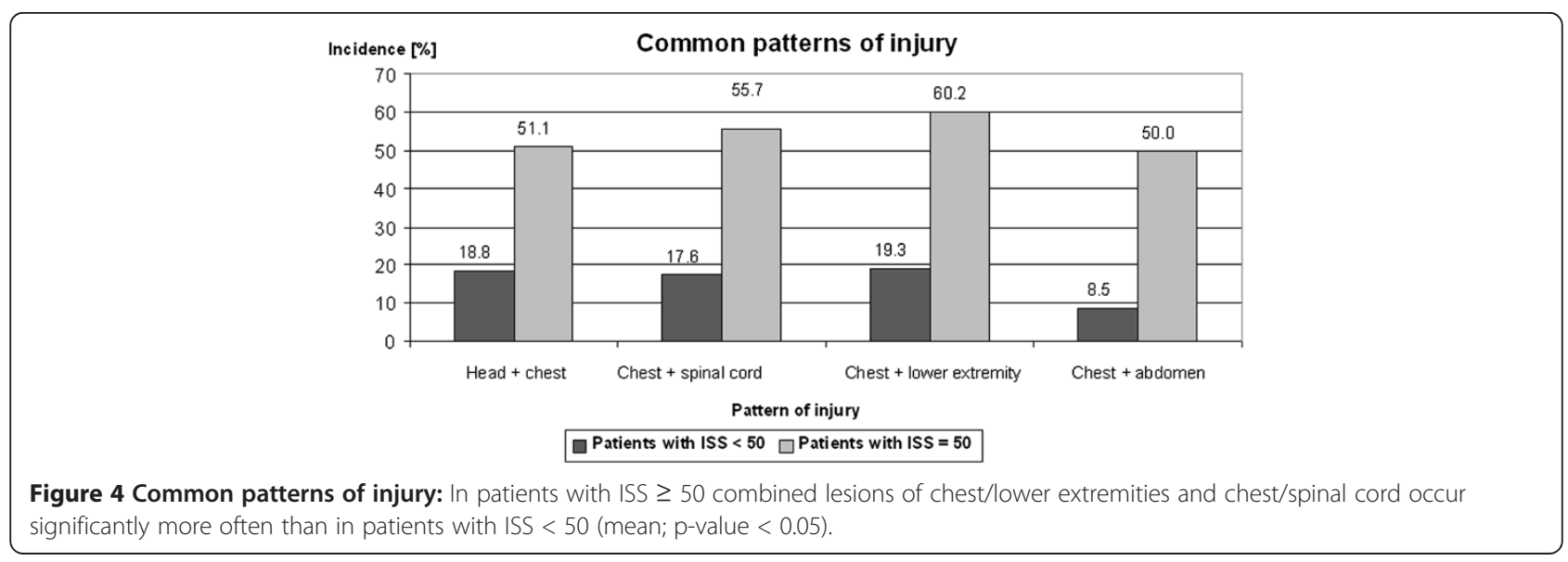




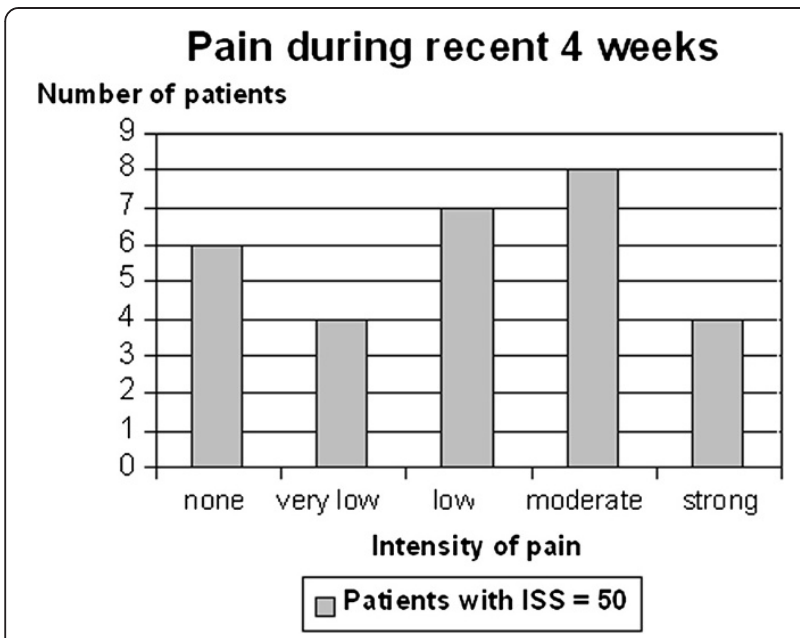

Figure 5 Pain during recent 4 weeks: A multi-dimensional evaluation using the POLO Chart questionnaire was performed in 29 out of 56 survivors to get an impression of health-based quality of life state. Time of evaluation was 3.6 years after trauma on average (range 18-78 months). Pain in recent four weeks was evaluated by using a score from "none" to "strong".

pattern and injury severity [16]. While in the Seventies $54 \%$ of victims died during hospital stay, in the Nineties $80 \%$ of victims died directly at place of accident. Many studies in the past showed that specific mechanisms of injury cause specific injury patterns, which can be diminished by specific security systems. The survivors with ISS $\geq 50$ (59 out of 88 ) were characterized by severe injuries of head/neck, thorax, abdomen and extremities. Their duration of hospitalisation (23 days) was extensively shorter than the results reported by van der Sluis in the Netherlands (30.4 days) and Frutiger in Switzerland [7,17].

Unintentional injuries are responsible for over 3.5 million deaths per year all over the world, making it the sixth leading reason for death [18]. Multi-organ failure/Multiorgan dysfunction syndrome (MOF/MODS) is today's main causative reason for death of severely injured patients. MOF/MODS can be defined as the development of potentially reversible physiologic derangement involving two or more organ systems not involved in the disorder that resulted in ICU admission, and arising in the wake of a potentially life-threatening physiologic insult [19]. In our study, in severely injured patients MOF was significantly more often seen than in the control group. The trauma registry of the German Society for Trauma Surgery announces the rate of MOF in all polytraumatized patients with $35 \%$, whereas in our hospital an amount of $54 \%$ was observed. Therefore, MOF is a decisive parameter for prognosis of clinical outcome. Failure of pulmonary, circulation, blood and/or cerebral nerve system showed an extraordinary amount in severely multiple-injured patients within this study. The blunt traumatic brain injury is known to be the most relevant course of death in this group of patients. Also SIRS was found significantly more often in patients with ISS $\geq 50$ than ISS $<50(12.5 \%$ vs. $3.8 \%$ ). Time of intubation in patients with ISS $\geq 50$ was almost twice as long as in patients with ISS $<50$. This seems to be explainable by an adequate pain therapy with drug induced breath depression as well as the higher frequency of traumatic chest injuries or the sequels of brain injuries. Additionally, in severely injured patients a high amount of operative revisions were necessary, therefore longer intubation duration avoided patients' stress related to multiple necessary re-intubations.

In our study, in severely injured patients with ISS $\geq 50$ mortality was extensively high (36\%), and $15 \%$ of these patients were "severely affected" when discharging from hospital. Therefore, with ongoing loss of mortality an increasing number of patients with lifetime handicaps and/or loss of working ability is expectable. Earlier surgical outcome studies focused on body function. From our point of view, for life-time quality after major trauma not only body functions are decicive, but also social, psychological and interpersonal aspects. There are different options to evaluate quality of life by using questionnaires: The global evaluation (e. g. SF-36) and the specific evaluation (e. g. FLQA-d). The POLO-chart questionnaire used in this study is based on a modular data evaluation and therefore a mixture including global and specific parts. Advantages of both methods are combined in the POLO-chart resulting in a maximum of information [20]. Nevertheless, weakening the results of this study is the fact that only severely injured patients with an ISS $\geq 50$ were evaluated using this score. In addition, results of scores like POLO-chart generally are just "flashlights" and repetitive evaluations are essential. Also a personal interview is supposed to be a good instrument to get further information about clinical outcome or to answer specific questions of importance. Unfortunately, just 13 out of 56 survivors filled in their phone number in POLO-chart, which is another limiting factor of the results of this study.

Actually, severely multiple-injured patients have a good survival prognosis, but post-traumatic quality of life is still not entirely satisfying. Especially psychological problems and chronic pain lead to a loss of quality in daily life. It is renowned that to know parameters influencing trauma-after-effects is essential for planning, organization, and implementation of rehabilitation programs in a high-specialized facility following major trauma [21]. One knows that about $50 \%$ of severely injured patients have one or more chronic problems, and that about $25 \%$ do not completely find their way back to work. In our study, a quarter of patients had interpersonal problems, $62 \%$ showed chronic pain (41\% strong or very strong pain) and $38 \%$ of patients are limited in 
activities of daily life related to pain. Also demographic factors, localization, severity and number of lesions are pivotal determinants of clinical outcome [22,23]. Nevertheless, none of these factors is able to predict which severely injured patients have good chances to recover completely and which not.

In recent literature rate of patients developing PTSD is approximately $10 \%$ [24]. In our observation, more than $40 \%$ of severely injured patients had beginning symptoms of PTSD. Insofar, PTSD is not just a fatal but rather frequent complication after major trauma, comparable with functional deficits following somatic leasions and/or pain. Our data show that early concomitant psychological therapy is necessary precondition to prevent development of fulminant PTSD. We confirm, that early start of multi-modal therapy concepts including psychological and pain therapy beginning within the ICU is prerequisite to avoid chronic pain syndrome and PTSD.

Concerning body functions more than half of patients declared a loss of function in activities of daily life and working ability. Remarkable was the fact that especially "bagatelle lesions" of the lower extremities were announced to be limiting in activities of daily life. Our data showed that leading leasions and treatment of these "huge" leasions are determining for survival. For functional outcome more often "little" and not perilous lesions result in decicive functional confinements. These findings lead us to begin with an early multi-modal treatment of "bagatelle lesions" including surgical treatment, physical therapy and occupational therapy, because especially these injuries often cause disability in daily life activities. Our results confirm findings of earlier studies that showed a huge amount of functional disability resulting from lesions of the lower extremities [25]. Investing in multi-modal therapy concepts is interesting not even from medical and ethic kind of view, but also under economic aspects in order to reduce the actually high rate of young patients who are unable to find back to work.

In conclusion, we suggest the consequent use of questionnaires like POLO chart or the International Classification of Functioning, Disability and Health (ICF) for early detection of patients with psychological problems, PTSD or problems in social field. These tools are quick, easy to answer and evaluable by commercially available computer programs, and without much effort useful data are obtainable. Thus, the ISS is an established tool to assess severity and prognosis of trauma, whereas prediction of clinical outcome cannot be deducted from this score.

Future studies should compare our local results with the overall German and international trauma registry data.

\section{Competing interests}

The authors declare that there is no actual or potential conflict of interest in relation to this article.

\section{Authors' contributions}

CVR drafted the manuscript. MRÖ contributed to acquisition of data, analysis and interpretation of data. SW, MRÜ and $\mathrm{CH}$ helped to search literature and to draft the manuscript. AW and VB participated in conception, design and coordination, and supervised the whole study. All authors read and approved the final manuscript.

\section{Acknowledgements}

The authors thank Katrin Olms for proofreading the manuscript.

\section{Author details}

${ }^{1}$ Department of Trauma Surgery, Murnau Trauma Center, Murnau 82418, Germany. 'Department of Anesthesiology, University Hospital Würzburg, Wurzburg, Germany.

Received: 16 October 2011 Accepted: 4 May 2013 Published: 15 May 2013

\section{References}

1. Mock C, Lormand JD, Goosen J, Joshipura M, Peden M: Guidelines for essential trauma care. Geneva, Switzerland: WHO; 2004.

2. Guenther S, Waydhas C, Ose C, Nast-Kolb D: Quality of multiple trauma care in 33 German and Swiss trauma centers during a 5-year period: regular versus on-call service. J Trauma 2003, 54(Suppl 5):973-978.

3. Dresing K: Recommended guidelines for diagnostics and therapy in trauma surgery. Eur J Trauma 2002, 27:137-150.

4. Barie PS, Hydo LJ, Fischer E: A prospective comparison of two multiple organ dysfunction/failure scoring systems for prediction of mortality in critical surgical illness. J Trauma 1994, 37:660-666.

5. Pettilä V, Pettilä M, Sarna S, Voutilanen P, Takkunen O: Comparison of multiple organ dysfunction scores in the prediction of hospital mortality in the critically ill. Crit Care Med 2002, 30:1705-1711.

6. Neugebauer EAM, Tecic T: Quality of life after severe injuries. Trauma Berufskrankh 2008, 10(Suppl 1):99-106.

7. van der Sluis $\mathrm{CK}$, Klasen $\mathrm{HJ}$, Eisma WH, ten Duis $\mathrm{HJ}$ : Major trauma in young and old: what is the difference? J Trauma 1996, 40:78.

8. Baker SP, O'Neill B, Haddon W, Long WB: The injury severity score. A method for describing patients with multiple injuries and evaluating emergency care. J Trauma 1974, 14:187-197.

9. Pirente $N$, Bouillon B, Schäfer B, Raum M, Helling HJ, Berger E, Neugebauer E: The polytrauma-outcome-(POLO-)chart. Unfallchirurg 2002, 105(Suppl 5):413-422.

10. Jennet $B$, Bond $M$ : Assessment of outcome after severe brain damage. Lancet 1975, 1(Suppl 7905):480-484.

11. Burghofer K, Lackner CK, Stolpe E, Schlechtriemen T, Mutschler WE: Quality of life five years after severe blunt trauma. Notfall Rettungsmedizin 2005, 8:552-563.

12. Lefering R: Trauma score systems for quality assessment. Eur J Trauma 2002, 2:52-63.

13. Ettedgui $E$, Bridges M: Posttraumatic stress disorder. Psychiatr Clin North Am 1985, 8(Suppl 1):89-103.

14. Meerding WJ, Looman CW, Essink-Bot ML: Distribution and determinants of health and work status in a comprehensive population of injury patients. J Trauma 2004, 56:150-161.

15. Holtslag HR, van Beeck EF, Lindeman E, Leenen LP: Determinants of longterm functional consequences after major trauma. J Trauma 2007, 62:919-927.

16. Otte D, Pohlemann T, Wiese B, Krettek C: Changes in the injury pattern of polytraumatized patients over the last 30 years. Unfallchirurg 2003, 106(Suppl 6):448-455.

17. Frutiger A, Ryf C, Bilat C: Five years follow-up of severely injured ICU patients. J Trauma 1991, 31:1216.

18. World Health Organization: Global burden of desease. 2011. http://www.who. int/healthinfo/global_burden_disease/en/. Accessed on March 1, 2011.

19. Marshall JC: The multiple organ dysfunction syndrome. In Surgical treatment: evidence-based and problem-oriented. Edited by Holzheimer RG, Mannick JA. Munich: Zuckschwerdt; 2011. 
20. Pirente N, Bouillon B, Schäfer B, Raum M, Helling HJ, Berger E: Systematic development of a scale for determination of health-related quality of life in multiple trauma patients. The polytrauma outcome (POLO) chart. Unfallchirurg 2002, 105(Suppl 7):605.

21. Simmel S, Bühren V: Surviving multiple trauma - what comes next? The rehabilitation of seriously injured patients. Unfallchirurg 2009. 112(Suppl 11):965-974.

22. Holbrook TL, Hoyt DB: The impact of major trauma: quality-of-life outcomes are worse in women than in men, independent of mechanism and injury severity. J Trauma 2004, 56:284-290.

23. Brennemann FD, Redelmeier DA, Boulanger BR: Long-term outcomes in blunt trauma: who goes back to work? J Trauma 1997, 42:778-781.

24. Breslau N, Kessler RC, Chilcoat HD, Schultz LR, Davis GC, Andreski P: Trauma and posttraumatic stress disorder in the community: the 1996 Detroit area survey of trauma. Arch Gen Psychiatry 1998, 55(Suppl 7):626-632

25. Braithewaite IJ, Boot DA, Patterson M, Robinson A: Disability after severe injury: five year follow up of a large cohort. Injury 1998, 29:55-59.

doi:10.1186/1752-2897-7-4

Cite this article as: von Rüden et al:: Outcome after severe multiple trauma: a retrospective analysis. Journal of Trauma Management \& Outcomes 2013 7:4

\section{Submit your next manuscript to BioMed Central and take full advantage of:}

- Convenient online submission

- Thorough peer review

- No space constraints or color figure charges

- Immediate publication on acceptance

- Inclusion in PubMed, CAS, Scopus and Google Scholar

- Research which is freely available for redistribution 